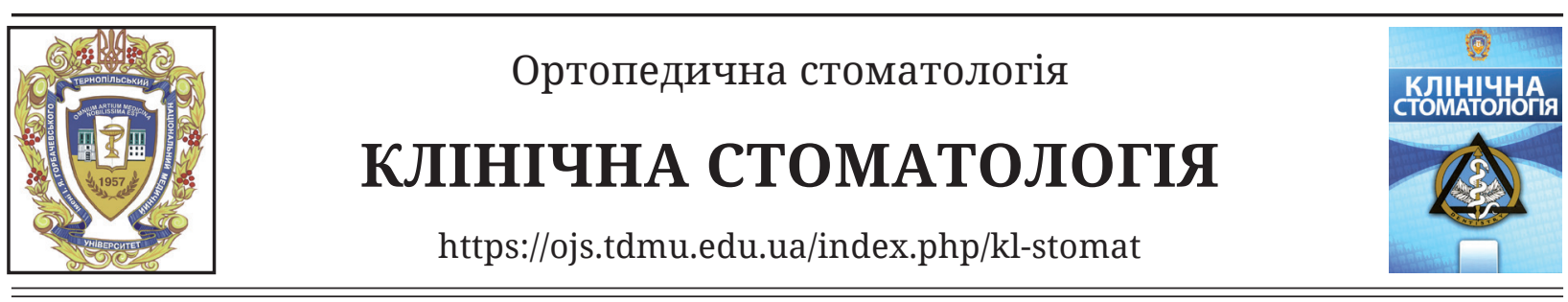

УдК 616.716.4-007.272

DOI 10.11603/2311-9624.2020.1.12041

(C). Ю. Михайлевич, В. Ф. Макєєв

Львівський національний медичний університет імені Данила Галицького

e-mail: martatyt@gmail.com

\title{
Оклюзійні інтерференції і скронево-нижньощелепні розлади
}

\section{ІНФОРМАЦІЯ}

Надійшла до редакціi//Received: 11.02.2021 p.

Ключові слова: скроневонижньощелепний суглоб; скронево-нижньощелепний розлад; оклюзійні інтерференціï.

\section{АНОТАЦІЯ}

Резюме. На сьогодні немає жодної узгодженої оклюзійної концепції, яка давала би відповідь на розробку ефективної технології нормалізації оклюзійних контактів при тому чи іншому варіанті прикусу. Багато в чому складність ситуації пояснюється існуючою до тепер «оклюзійною нез'ясованістю», яка затруднює оптимальний вибір тактики лікування оклюзійної інтерференції.

Мета дослідження - проаналізувати джерела науково-медичної інформації відносно сучасних поглядів щодо впливу оклюзійних інтерференцій на скронево-нижньощелепні розлади.

Матеріали і методи. Бібліографічний аналіз із питань взаємодії оклюзії і скронево-нижньощелепних суглобів.

Результати досліджень та їх обговорення. Класична гнатологічна теорія заснована на принципах концепції середньостатистичного «ідеального» прикусу, і на основі якої побудований середньоанатомічний артикулятор, відходить на задній план. Стабільні трансверзальні та вертикальні положення нижньої щелепи забезпечують фісурно-горбкові контакти жувальних зубів, які перешкоджають зміщенню нижньої щелепи, здійснюючи «оклюзійний захист СНщС». Напрямні площини зубів у сагітальному та трансверзальному напрямках впливають на характер оклюзійних рухів нижньої щелепи. Оклюзійні порушення, особливо після неадекватного протезування, своїм впливом на скронево-нижньощелепні розлади можуть проявитися через 4-6 років, що пов’язано з високими пристосувальними можливостями як м'язів, так скронево-нижньощелепних суглобів.

Висновки. Необхідно зазначити недостатність даних про закономірності впливу оклюзії у динаміці патологічних процесів на функцію жувальних м’язів і скронево-нижньощелепні суглоби, а також в питаннях донозологічної діагностики порушень функцій жувальних м’язів і СНщС в ортопедичній стоматології.
Вступ. Загальновідомо, що зубощелепно-лицева система функціонує у результаті складних взаємодій щелеп, жувальних м’язів, зубів, скронево-нижньощелепних суглобів (СНЩС), зв’язок якої забезпечується системою тригемінального нерва з усіма його нейрогенними компонентами, які тісно пов'язані 3 центральними ядрами головного мозку.
Патологія прикусу, дисфункція СНЩС, пародонтальні та краніомандибулярні проблеми і багато інших супутніх факторів складають неповний перелік, що входить у поняття скронево-нижньощелепних розладів. Проте на тепер немає ні одної сучасної оклюзійної концепції, яка давала би відповідь на розпрацювання ефективної технології нормалізації оклюзій- 
них контактів при тому чи іншому варіанті прикусу. Багато в чому складність ситуації пояснюється існуючою до тепер «оклюзійною нез'ясованістю", яка затруднює оптимальний вибір тактики лікування оклюзійної інтерференції [1].

Різноманіття оклюзійних теорій підтверджує складність проблеми. Класична гнатологічна теорія заснована на принципах дії із запропонованою автором концепцією середньостатистичного «ідеального» прикусу, і на основі якої побудований авторський артикулятор, відходить на задній план.

Адже підтверджено, що прикус людини і рухи нижньої щелепи є суто індивідуальними і такими же неповторними як візерунки пальців або будова вушних раковин [2].

На тепер із усіх існуючих теорій найбільшого значення придається гнатологічній філософії і філософії, заснованій на стані м’язів. Із них головну увагу приділяється нейром'язовій концепції, в рамках якої також існує декілька теорій нейром'язової оклюзії у сполученні $з$ дисфункціями СНЩС. Наслідки порушення оклюзії можуть проявлятися у будь-якій [3] ланці зубощелепної системи [4-6].

Метою дослідження було проаналізувати джерела науково-медичної інформації відносно сучасних поглядів щодо впливу оклюзійних інтерференцій на скронево-нижньощелепні розлади.

Матеріали і методи. Бібліографічний аналіз з питань взаємодії оклюзії і скронево-нижньощелепних суглобів.

Результати досліджень та їх обговорення. Існують численні концепції, які по-різному констатують, яка ланка цієї системи є ведучою, направляючою. Проте всі дослідники вважають на сьогодні, що СНЩС зумовлює різноманіття рухів нижньої щелепи. Неможливо заперечувати, що СНЩС створює напрямні площини для рухів нижньої щелепи, забезпечуючи їі стабільне дистальне положення відносно верхньої щелепи (задній обмежувальний компонент). Різцеве перекриття створює передній обмежувальний компонент. Визначення й установка цих компонентів - основа роботи “суглобових" артикуляторів. У зв'язку 3 розвитком теорії оклюзійного програмування, заснованого на принципах ковзаючих рухів нижньої щелепи, всі рухи її пов'язані $з$ оклюзією зубних рядів. Стабільні трансверзальні та вертикальні положення нижньої щелепи забезпечують фісурно-горбикові кон- такти жувальних зубів, які перешкоджають зміщенню нижньої щелепи, здійснюючи «оклюзійний захист СНЩС». Напрямні площини зубів у сагітальному та трансверзальному напрямках впливають на характер оклюзійних рухів нижньої щелепи [4].

Між іншим, сучасні уявлення на рахунок функціональної оклюзії не відображають новітні дані про будову оклюзійних поверхонь зубних рядів. Закономірності будови оклюзійної поверхні зубних рядів сформульовані R. Ganau у вигляді «артикуляційної п’ятірки» до тепер не переглядалися.

На характер оклюзійних контактів зубів при рухах нижньої щелепи впливають багато чинників, головні з яких є морфологія жувальної поверхні бічних зубів, рівень висоти їх горбиків і ступінь різцевого перекриття [7-10].

Серед наслідків можливих патологічних процесів відносно СНР виділяють три основні групи: порушення цілості зубних рядів, патологічні процеси в пародонті й морфологічні втрати твердих тканин зубів (надмірна стертість, клиноподібні дефекти тощо). Проте причин, як і зон ураження, в дійсності є значно більше.

Вони не обмежуються ротовою порожниною і можуть виникати далеко за межами зубощелепної системи.

Для тривалого виконання зубощелепною системою своїх функцій необхідні гармонійні оклюзійні контакти не лише в центральній оклюзії, але також при сагітальних і трансверзальних рухах нижньої щелепи, тобто при всіх видах артикуляції. І це забезпечується достатньо складною анатомією і рельєфом контактуючих поверхонь зубів-антагоністів [11, 12].

Перші порушення цілості коронкової частини постійних зубів, що виникають унаслідок карієсу, діагностуються у дитячому віці.

За даними літератури, перші постійні моляри уражаються карієсом з локалізацією на оклюзійній поверхні, що вимагає терапевтичного лікування, пов'язаного з пломбуванням у 75-80 \% дітей. Проте лікування, яке здійснено без відновлення правильної анатомічної будови коронкової частини, може призвести до значних деформацій. Ураховуючи, що шості зуби, які прорізалися першими з постійних зубів, надають суттєвий вплив на міжальвеолярну висоту, становлення прикусу і подальший розвиток зубощелепної системи, стає зрозумілим необхідність адекватного моде- 
лювання горбків, фісур. Порушення оклюзії у таких ситуаціях залишається без уваги і з боку лікаря. На жаль, досить часто спеціалісти, перевіривши змикання зубів у центральній оклюзії, цим і обмежуються і не здійснюють детальний аналіз оклюзійно-артикуляційних взаємовідносин за нестачею часу або небажання. У віддалені терміни унаслідок такого пломбування формуються неправильний стереотип рухів із розвитком дисфункціональних станів рухів з можливим розвитком змін у роботі СНЩС та інших елементів зубощелепної системи [13-15].

Іншою причиною артикуляційних порушень може бути неправильне формування бічних контактних пунктів зубів з ураженням апроксимальних поверхонь. За відсутності або при некоректному розташуванні міжзубного контакту можливе переміщення причинного або поряд стоячого зуба у бік дефекту, що, у свою чергу, призводить до вертикального зміщення антагоністів. Така деформація формується поступово, як правило, без скарг, призводячи у наступному до розвитку парафункцій.

Навіть при ідеально встановленій пломбі чи вкладці у процес оклюзії включається фактор міцності й стабільності самого пломбувального матеріалу, що може призвести до його стертості та спровокувати порушення оклюзійних співвідношень.

Оклюзія не є стабільною і незмінною, ї̈ зміни залежать від зубних рядів, жувальних м'язів, СНЩС i їх нейром'язового забезпечення.

Оклюзійна травма можлива із-за супраконтактів на передніх зубах, при завищених пломбах, вкладках, незадовільного виготовлення коронок, незнімних та знімних протезів, ортодонтичних заходах.

Оклюзійні порушення, особливо після неадекватного протезування, своїм впливом на скронево-нижньощелепні розлади можуть проявитися через 4-6 років, що пов’язано з високими пристосувальними можливостями як м’язів, так скронево-нижньощелепних суглобів.

A. N. Buman et al. [16] навели дані про адаптаційні та прогресуючі адаптаційні механізми тканин СНЩС та жувальної мускулатури, що призводять до ремоделювання (перебудови) тканин СНЩС. Автори розглянули СНЩС як окремий вид біологічної мікросистеми, виділивши поверхні суглобової порожнини, диск, біламінарну зону й оцінили це як стабілізуючий амортизаційний механізм, функція якого полягає у забезпеченні стабільного правильного положення головки нижньої щелепи в суглобовій ямці при різних фазах їі руху. Внутрішньосуглобовий диск, володіючи адаптаційними властивостями, пристосований та проходить етапи моделювання під час формування і зростання та ремоделювання на етапі сформованого зростання. Зміна суглобових поверхонь і диска при процесах ремоделювання призводять до порушень структури тканин та розвитку шумових явищ, зміщення диска, його вивиху із збереженням зворотності процесів, тобто можливості самовправляння. При тривалому перебігу адаптативні процеси ремоделювання спричиняють незворотність процесу. Таку аналогію автори подають у своïx дослідженнях із м'язово-зв'язковим компонентом жувальної системи $[17,18]$.

Необхідно зазначити недостатність даних про закономірності впливу оклюзії у динаміці патологічних процесів на функцію жувальних м'язів і скронево-нижньощелепні суглоби, а також в питаннях донозологічної діагностики порушень функцій жувальних м’язів і СНЩС в ортопедичній стоматології [19-22].

Наявні у розпорядженні стоматологів різноманітні методи дослідження вельми складні й не завжди дають можливості правильно поставити діагноз [23-26]. Складність діагностики і лікування нейром'язових та артикуляційно-оклюзійних синдромів пов'язана з відсутністю єдиної думки про походження цих порушень, єдиних методів патогенетичної терапії і подібною клінічною картиною різних ïx форм, а розпрацьовані методи лікування виявляються малоефективними.

Висновки. При здійсненні оклюзійної корекції необхідно створювати адекватну статичну і динамічну оклюзію, що перебуває у тісному контакті з нейром'язовою системою. Відсутність нейром'язової та оклюзійно-артикуляційної рівноваги може призвести до розвитку «оклюзійного неврозу» і сприяти розвитку фізичних та психічних проблем. 
(). Ю. Михайлевич, В. Ф. Макеев

Львовский национальный медицинский университет имени Данила Галицкого

\section{Окклюзионные интерференщии и височно-нижнечелюстной сустав}

Резюме. На сегодняшний день нет ни одной согласованной окклюзионной концепции, которая давала бы ответ на разработку эффективной технологии нормализации окклюзионных контактов при том или ином варианте прикуса. Во многом сложность ситуации объясняется существующей до сих пор «окклюзионной неясностью», которая затрудняет оптимальный выбор тактики лечения окклюзионной интерференции.

Цель исследования - проанализировать источники научно-медицинской информации относительно современных взглядов на влияние окклюзионных интерференций на височно-нижнечелюстные расстройства.

Материалы и методы. Библиографический анализ по вопросам взаимодействия окклюзии и височно-нижнечелюстных суставов.

Результаты исследований и их обсуждение. Классическая гнатологическая теория основана на принципах концепции среднестатистического «идеального» прикуса, на основе которой построен среднеанатомический артикулятор, отходит на задний план. Стабильные трансверзальные и вертикальные положения нижней челюсти обеспечивают фиссурно-бугорочные контакты жевательных зубов, которые препятствуют смещению нижней челюсти, осуществляя «окклюзионную защиту ВНЧС». Направляющие плоскости зубов в сагиттальном и трансверзальном направлениях влияют на характер окклюзионных движений нижней челюсти. Окклюзионные нарушения, особенно после неадекватного протезирования, своим влиянием на височно-нижнечелюстные расстройства могут проявиться через 4-6 лет, что связано с высокими приспособительными возможностями как мышц, так височнонижнечелюстных суставов.

Выводы. Следует отметить недостаточность данных о закономерностях влияния окклюзии в динамике патологических процессов на функцию жевательных мышц и височно-нижнечелюстного сустава, а также в вопросах донозологической диагностики нарушений функций жевательных мышц и ВНЧС в ортопедической стоматологии.

Ключевые слова: височно-нижнечелюстной сустав; височно-нижнечелюстные расстройства; окклюзия.

CM. Yu. Mykhailevych, V. F. Makeev

Danylo Halytskyi Lviv National Medical University

\section{Occlusive interference and temporomandibular joint}

Summary. Nowadays there is no modern occlusal concept that would provide an answer to the development of effective technology for normalization of occlusal contacts in one or another variant of occlusion. The complexity of the situation is largely due to the existing "occlusal ambiguity", which makes it difficult to choose the optimal tactics for the treatment of occlusal interference.

The aim of the study - to analyze the sources of scientific and medical information on modern views on the impact of occlusal interference on the temporomandibular disorders.

Materials and Methods. Bibliographic analysis of the interaction of occlusion and temporomandibular joints. Results and Discussion. Classical gnathological theory is based on the principles of the concept of the average "ideal" bite, and on the basis of which the average anatomical articulator is built, recedes into the background. Stable transverse and vertical positions of the mandible provide fissure-tubercle contacts of the masticatory teeth, which prevent the displacement of the mandible, providing "occlusive protection of the TMJ". The guide planes of the teeth in the sagittal and transverse directions affect the nature of occlusal movements of the mandible. Occlusive disorders, especially after inadequate prosthetics, can manifest themselves in temporomandibular disorders in 4-6 years, which is associated with high adaptability of both muscles and temporomandibular joints.

Conclusions. It should be noted that there is a lack of data on the patterns of occlusion in the dynamics of pathological processes on the function of the masticatory muscles and temporomandibular joints, as well as in the pre-nosological diagnosis of masticatory muscle disorders and TMJ in orthopedic dentistry.

Key words: temporomandibular joint; temporomandibular disorder; occlusion. 


\section{СПИСОК ЛІТЕРАТУРИ}

1. Ронкин К. Дисфункция ВНЧС и «оклюзионная неразбериха» / К. Ронкин // Dentalmarket. - 2014. № 2. - С. 51-56.

2. Скронево-нижньощелепні розлади / В. Ф. Макєєв, У. Д. Телішевська, В. Я. Шибінський [та ін.]. - Львів: Кварт, 2018. - 404 с.

3. Хватова В. А. Окклюзия и патология окклюзии / В. А. Хватова, Н. Д. Капп, Н. В. Барретт. - М. : Азбука, 2005. - 235 c.

4. Макєєв В. Ф. Сучасні погляди на етіологічні чинники розвитку скронево-нижньощелепних розладів (огляд літератури) / В. Ф. Макєєв, М. Ю. Олійник // Український стоматологічний альманах. - 2018. № 2. - С. 39-53.

5. Correspondence between dental and skeletal maturity parameters among patients with different sagittal relationships at the end of puberty period / M. Goncharuk-Khomyn, E. Akleyin, I. Zhulkevych [et al.] // J. Int. Dent. Med. Res. - 2020. - Vol. 13 (1). - P. 223-228.

6. Determination of individual cephalometric characteristics of theocclusal plane in Ukrainian young men and young women with orthognatic bite / M. O. Dmitriev, I. V. Gunas, I. V. Dzevulska, I. V. Zhulkevych // Biomedical and Biosocial Anthropology. - 2018. - Vol. 4 (33). - P. 5-11.

7. Хватова В. А. Клиническая гнатология / В. А. Хватова. - М. : Медицина, 2007. - 295 с.

8. Рябов С. В. Методика изучения особенностей строения окклюзионных кривых при ортогнатическом прикусе / С. В. Рябов // Стоматология. - 2007. № 4. C. 59-66.

9. Ожоган Р. 3. Сучасні методи діагностики та лікування хворих із дефектами зубних рядів, ускладненими розладами скронево-нижньощелепного суглоба / Р. 3. Ожоган, М. М. Рожко, 3. Р. Ожоган // Український стоматологічний альманах. - 2017. № 1. - С. 37-41.

10. Брагин Е. А. Роль окклюзионных нарушений в развитии заболеваний височно-нижнечелюстного сустава, дисфункций жевательных мышц и заболеваний пародонта / Е. А. Брагин, А. А. Долгалев, Н. В. Брагарева // Научное обозрение. Медицинские науки. - 2015. - № 1. - С. 90-91.

11. Славичек Р. Жевательный орган. Функции и дисфункции / Р. Славичек. - М. : Азбука стоматолога, 2008. -543 c.

12. Ratdif F. S. Type and incidence of cracks in posterior teeth / F. S. Ratdif, I. M. Becker, L. Quinn // J. Prosther. Dent. - 2001. - № 86. - P. 168-172.

13. Соловьев А. А. Травматическая окклюзия. Возможные факторы риска и ее патогенез / А. А. Соловьев, Н. Н. Аболмасов // Часть I и II. Институт стоматологии. - 2013. - № 4. - С. 41-54.

14. Клинические проявления патологии височнонижнечелюстных суставов и жевательных мышц

\section{REFERENCES}

1. Ronkin, K. (2014). Disfunktsiya VNCHS i "oklyuzionnaya nerazberikha» [Dysfunction of VNChS у пациентов с нарушениями окклюзии зубов и зубных рядов / А. В. Лепилин, В. В. Коннов, Е. А. Багарян, А. Р. Арушанян // Саратовский научно-медицинский журнал. - 2010. - № 6 (2). - С. 405-410.

15. Якупов Б. Р. Диагностика и лечение мышечносуставной дисфункции височно-нижнечелюстного сустава с болевым синдромом, связанной с окклюзионными нарушениями, с применением сплинт-терапии / Б. Р. Якупов, Л. П. Герасимова // Медицинский вестник Башкортостана. - 2013. № 4. - C. 46-49.

16. Bumann A. The significance of the fissurae petrotympanica, petrosquamosa and tympanosquamosa for disk displacements in the temporomandibular joint / A. Bumann, G. Groot Landeweer, P. Brauckmann // Fortschr. Kieferorthop. - 1991. - Vol. 52 (6). - P. 359-365. 17. Mills D. K. Morphologic, microscopic, and immunohistochemical investigations into the function of the primate TMJ disk / D. K. Mills, D. J. Fiandaca, R. P. Scapino // J. Orofac Pain. - 1994. - Vol. 8. - P. 136-154. 18. Okeson G. P. Management of Temporomandibular. Disorders and Occlusion / G. P. Okeson. - 7th edn. Mosby, 2003. - P. 149-180.

19. Slavichek R. Relationship between occlusion and temporomandibular disorders: implications for the gnatologist / R. Slavichek // Am. J. Orthod. Dentofacial. Orthop. - 2011. - № 1 (139). - P. 10-14.

20. Talon cups causing occlusal trauma and acute apical periodontotos report of a case / J. Segura-Egea,

A. Jimenez-Rubio, E. Velasco-Ortega, V. Rios-Santos // Dent. Traumotal. - 2003. - № 1 (19). - P. 55-59.

21. Graff-Radford S. B. Myofascial pain: diagnosis and management / S. B. Graff-Radford // Curr. Pain Headache Rep. - 2004. - Vol. 8. - P. 463.

22. Miller L. Symbosis of eathetics and occlusion: Thought and opinions of a master of sthesicdentisty / L. Miller // J. Esthet. Dent. - 1999. - № 11. - P. 155-165.

23. Пантелеев В. Д. Диагностика нарушений артикуляции нижней челюсти у пациентов с дисфункциями височно-нижнечелюстного сустава / В. Д. Пантелеев, Е. М. Рощин, С. В. Пантелеев // Стоматология. - 2011. - № 1. - С. 52-57.

24. Макєєв В. Ф. Визначення можливих факторів, які впливають на розвиток скронево-нижньощелепних розладів хворих за їх анамнестичними даними / В. Ф. Макєєв, О. Д. Телішевська, М. Ю. Михайлевич // Сучасна стоматологія. - 2019. - № 4 (98). - С. 64-67. 25. Височно-нижнечелюстные расстройства / Д. Манфредини. - М. : Азбука, 2013. - 500 с.

26. Особливості оклюзійної терапії при функціональних розладах скронево-нижньощелепних суглобів / В. Ф. Макєєв, Ю. О. Риберт, В. Я. Шибінський [та ін.] // Актуальні проблеми сучасної медицини: Вісник Української медичної стоматологічної академії. - 2020. - Т. 20, № 3 (71). - С. 249-257. and "oklyuzionny confusion"]. Dentalmarket, 2, 51-56. [in Russian]. 
2. Makieiev, V.F., Telishevska, U.D., Shybinskyy, V.Y., Telishevska, O.D., \& Kulinchenko, R.V. (2018). Skronevo-nyzhnioshchelepni rozlady: monohrafia [Temporomandibular disorders: monograph]. Lviv: Kvart [in Ukrainian].

3. Hvatova, V.A., Kapp, N.D., \& Barrett, N.V. (2005). Okklyuziya i patologiya okklyuzii [Occlusion and pathology of occlusion]. Moscow: Azbuka [in Russian].

4. Makieiev, V.F., \& Oliinyk, M.Yu. (2018). Suchasni pohliady na etiolohichni chynnyky rozvytku skronevo-nyzhnoshchelepnykh rozladiv (ohliad literatury) [Modern views on the etiological factors of temporomandibular disorders (review of the literature)]. Ukrainskyi stomatolohichnyi almanakh Ukrainian Dental Almanac, 2, 39-53 [in Ukrainian].

5. Dmitriev, M.O., Gunas, I.V., Dzevulska, I.V., \& Zhulkevych, I.V. (2018). Determination of individual cephalometric characteristics of theocclusal plane in Ukrainian young men and young women with orthognatic bite. Biomedical and Biosocial Anthropology, 4 (33), 5-11.

6. Goncharuk-Khomyn, M., Akleyin, E., Zhulkevych, I., Nahirnyi, Y., Brekhlichuk, P., Mochalov, Y., \& Stoika, O. (2020). Correspondence between dental and skeletal maturity parameters among patients with different sagittal relationships at the end of puberty period. J. Int. Dent. Med. Res., 13 (1), 223-228.

7. Hvatova, V.A. (2007). Clinical gnatologiya [Clinical gnathology]. Moscow: Medicine [in Russian].

8. Ryabov, S.V. (2007). Metodika izucheniya osobennostey stroyeniya okklyuzionnykh krivykh pri ortognaticheskom prikuse [A technique of studying of features of a structure the okklyuzionnykh of curves at an ortognatichesky bite]. Stomatologiya - Stomatology, 4, 59-66 [in Russian].

9. Ozhohan, R.Z. (2017). Suchasni metody diahnostyky ta likuvannia khvorykh iz defektamy zubnykh riadiv, uskladnenymy rozladamy skronevonyzhnoshchelepnoho suhloba [Suchasni metody diahnostyky ta likuvannya khvorykh iz defektamy zubnykh ryadiv, uskladnenymy rozladamy skronevo-nyzhn'oshchelepnoho suhloba]. Ukrainskyi stomatolohichnyi almanakh - Ukrainian Dental Almanac, 1, 37-41 [in Ukrainian].

10. Bragin, E.A., Dolgalev, A.A., \& Bragareva, N.V. (2015). Rol okklyuzionnyih narusheniy v razvitii zabolevaniy visochno-nijnechelyustnogo sustava, disfunktsiy jevatelnyih myishts i zabolevaniy parodonta [The role of occlusive disorders in the development of diseases of the temporomandibular joint, dysfunctions of the masticatory muscles and periodontal disease]. Nauchnoe obozrenie. Meditsinskie nauki - Scientific Review. Medical sciences, 1, 90-91 [in Russian].

11. Slavichek, R. (2008). Zhevatelnyy organ. Funktsii $i$ disfunktsii [Chewing body. Functions and dysfunctions]. Moscow: Azbuka stomatologa [in Russian].

12. Ratdif, F.S., Becker, I.M., \& Quinn, L. (2001). Type and incidence of cracks in posterior teeth. J. Prosther. Dent., 86, 168-172.

13. Solovev, A.A., \& Abolmasov, N.N. (2013). Travmaticheskaya okklyuziya. Vozmozhnyiye faktoryi riska i yeye patogenez. Chast I i II. [Traumatic occlusion. Possible risk factors and its pathogenesis]. Part I and II. Institut stomatologii - Institute of Dentistry, 4, 41-54 [in Russian].
14. Lepilin, A.V., Konnov, V.V., Bagaryan, E.A., \& Arushanyan, A.R. (2010). Klinicheskie proyavleniya patologii visochno-nijnechelyustnyih sustavov i jevatelnyih myishts $\mathrm{u}$ patsientov $\mathrm{s}$ narusheniyami okklyuzii zubov i zubnyih ryadov [Clinical manifestations of pathology of the temporomandibular joints and masticatory muscles in patients with impaired occlusion of teeth and dentition]. Saratovskiy nauchno-meditsinskiy jurnal - Saratov Scientific Medical Journal, 6 (2), 405-410 [in Russian].

15. Yakupov, B.R., \& Gerasimova, L.P. (2013). Diagnostika i lechenie myishechno-sustavnoy disfunktsii visochnonijnechelyustnogo sustava s bolevyim sindromom, svyazannoy s okklyuzionnyimi narusheniyami, $\mathrm{s}$ primeneniem splint-terapii [Diagnostics and treatment of musculo-articular dysfunction of the temporomandibular joint with pain associated with occlusive disorders using splint therapy]. Meditsinskiy vestnik Bashkortostana - Medical Bulletin of Bashkortostan, 4, 46-49 [in Russian].

16. Bumann, A., Landeweer, G.G., \& Brauckmann, P. (1991). The significance of the fissurae petrotympanica, petrosquamosa and tympanosquamosa for disk displacements in the temporomandibular joint. Fortschr. Kieferorthop., 52 (6), 359-365. DOI: 10.1007/ BF02166634

17. Mills, D.K., Fiandaca, D.J., \& Scapino, R.P. (1994). Morphologic, microscopic, and immunohistochemical investigations into the function of the primate TMJ disk. J. Orofac Pain., 8, 136-154.

18. Okeson, G.P. (2003). Management of Temporomandibular. Disorders and Occlusion. 7th edn. Mosby (pp. 149-180).

19. Slavichek, R. (2011). Relationship between occlusion and temporomandibular disorders: implications for the gnatologist. Am. J. Orthod. Dentofacial. Orthop., 1 (139), 10-14. DOI: 10.1016/j.ajodo.2010.11.011

20. Segura-Egea, J., Jimenez-Rubio, A., Velasco-Ortega, E., \& Rios-Santos, V. (2003). Talon cups causing occlusal trauma and acute apical periodontotos report of a case. Dent Traumotal., 1 (19), 55-59. DOI: 10.1034/j.16009657.2003.00110.x

21. Graff-Radford, S.B. (2004). Myofascial pain: diagnosis and management. Curr. Pain Headache Rep., 8, 463. DOI: 10.1007/s11916-004-0068-y

22. Miller, L. (1999). Symbosis of eathetics and occlusion: Thought and opinions of a master of sthesicdentisty. J. Esthet. Dent., 11, 155-165.

23. Panteleev, V.D., Roschin, E.M., \& Panteleev, S.V. (2011). Diagnostika narusheniy artikulyatsii nijney chelyusti u patsientov s disfunktsiyami visochno-nijnechelyustnogo sustava [Diagnosis of articulation disorders of the mandible in patients with temporomandibular joint dysfunctions]. Stomatologiya - Dentistry, 1, 52-57 [in Russian].

24. Makeev, V.F., Telyshevska, O.D., \& Mykhailevych, M.Yu. (2019). Vyznachennia mozhlyvykh faktoriv, yaki vplyvaiut na rozvytok skronevo-nyzhnoshchelepnykh rozladiv khvorykh za yikh anamnestychnymy danymy [Determination of possible factors influencing the development of temporomandibular disorders of patients according to their anamnestic data]. Suchasna stomatolohiia - Modern Dentistry, 4 (98), 64-67 [in Ukrainian].

25. Manfredini, D. (2013). Visochno-nizhnechelyustnyie 
rasstroystva [Temporomandibular disorders]. Moscow: Azbuka [in Russian].

26. Makeev, V.F., Rybert, Yu.O., Shybinskyy, V.Ya., Kliuchkovska, N.R., \& Kyrmanov, O.S. (2020). Osoblyvosti okliuziinoi terapii pry funktsionalnykh rozladakh skronevo-nyzhnoshchelepnykh suhlobiv [Features of occlusal therapy in functional disorders of temporomandibular joints]. Aktualni problemy suchasnoi medytsyny: Visnyk Ukrainskoi medychnoi stomatolohichnoi akademii - Actual Problems of the Modern Medicine: Bulletin of Ukrainian Medical Dentistry Academy, 3 (71), 249-257. DOI: https://doi. org/10.31718/2077-1096.20.3.249 [in Ukrainian]. 